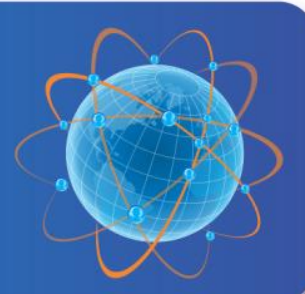

\title{
Pengelolaan Sampah Berbasis Modal Sosial Masyarakat
}

Authors : Rio Syahli, Bintarsih Sekarningrum

Published by : Departemen of Sociology, Faculty of Social and Political Science, Universitas Padjadjaran

Accepted : March 2017; Approved : April 2017

Sosiogobal: Jumal Pemikiran dan Penelitian Sosiologi is the Department of Sociology, Faculty of Social and Political Science, Universitas Padjadjaran flagship journal. The Sosioglobal journal founded in 2016 with the mission to publish original works of interest to the discipline of sociology in general, sociological thinking, new theoretical developments, results of research that enhance understanding of fundamental social processes, and methodological innovations. We are welcome a research article, working paper, theoretical/conceptual and methodological review to submit to our journal. In addition, we are accept relevant book review that currently publish and enrich sociological perspectives. Please submit article to http://jurnal.unpad.ac.id/sosioglobal

To cite this article :

Syahli, Rio and Bintarsih Sekarningrum.2017.Pengelolaan Sampah Berbasis Modal Sosial Masyarakat.Sosioglobal : Jurnal Pemikiran dan Penelitian Sosiologi 1(2):143-151. 


\title{
PENGELOLAAN SAMPAH BERBASIS MODAL SOSIAL MASYARAKAT
}

\author{
Rio Syahli ${ }^{1}$, Bintarsih Sekarningrum ${ }^{2}$ \\ ${ }^{1}$. Prodi Sosiologi, Fakultas Ilmu Sosial dan Ilmu Politik, Universitas Padjadjaran \\ riosyahli@yahoo.com
}

\begin{abstract}
ABSTRAK
Sampah merupakan permasalahan utama yang dihadapi Indonesia terutama di kota-kota besar yang memiliki tingkat aktivitas dan kepadatan tinggi serta pembangunan infrastruktur yang pesat. Salah satu cara menghadapi permasalahan sampah di kota besar adalah memberlakukan sistem pengelolaan sampah di masyarakat dan membangun sarana tempat pengolahan sampah terpadu (TPST). Penelitian bertujuan mendeskripsikan pengelolaan sampah melalui modal sosial masyarakat. Metode yang digunakan yaitu kualitatif. Informan adalah aparat pemerintah, tokoh masyarakat, kelompok dan warga masyarakat. Hasil penelitian menunjukkan bahwa pada aspek jaringan, dengan adanya kesamaan latar belakang (bonding), adanya kerjasama antara berbagai pihak (Bridging), dan relasi sosial (Linking) antara berbagai pihak dalam pelaksanaan pengelolaan sampah, maka sistem pengelolaan sampah dapat disosialisasikan dan diterapkan. Pada aspek norma, pengelolaan sampah berjalan sesuai dengan aturan bersama dan nilai yang berlaku. Pada aspek kepercayaan, adanya respon positif dari masyarakat terhadap pengelolaan sampah khususnya dalam mewujudkan Kawasan Bebas Sampah (KBS). Simpulan penelitian, sistem penegelolaan sampah akan efektif apabila berbasiskan modal sosial masyarakat. Modal sosial merupakan kekuatan sosial masyarakat dalam mencapai tujuan bersama yaitu Kawasan Bebas Sampah.
\end{abstract}

Kata kunci : pengelolaan sampah, modal sosial, masyarakat

\begin{abstract}
Garbage is the main problem faced by Indonesia especially in big cities which has high activity and density level also rapid infrastructure development. One way to deal with garbage problem in big cities is to impose a waste management system in the community and build the integrated waste treatment facilities (TPST). The study aims to describe waste management through social capital of society. The method used in this research is qualitative method. The informants of research data are government officials, community leaders community groups and citizens. The results showed that in the network aspect, with the existence of the similarity of the background (Bonding), the existence of cooperation between various parties (Bridging), and social relation (Linking) between various parties in the implementation of waste management, the waste management system can be socialized and applied. In the aspect of norms, waste management runs in accordance with common rules and values applicable. In the aspect of trust, there is a positive response from the community on waste management, especially in realizing the Zero Waste Area. Conclusion of the research, waste management system will be effective if based on social capital of society. Social capital is the social power of the community in achieving the common goal of the Zero Waste Area.
\end{abstract}

Keywords: waste management, social capital, society

\footnotetext{
${ }^{2}$ Prodi Sosiologi, Fakultas Ilmu Sosial dan Ilmu Politik, Universitas Padjadjaran bintarsih.sekarningrum@unpad.ac.id
} 


\section{PENDAHULUAN}

Kota Bandung salah satu kota terbesar di Indonesia tentunya tidak terlepas dari berbagai macam polemik permasalahan, salah satunya adalah sampah. Sampah saat ini sudah menjadi suatu permasalahan yang seringkali terjadi di setiap kota besar. Volume sampah di Kota Bandung kian hari kian bertambah seiring dengan pertambahan jumlah penduduk dan kemajuan teknologi.

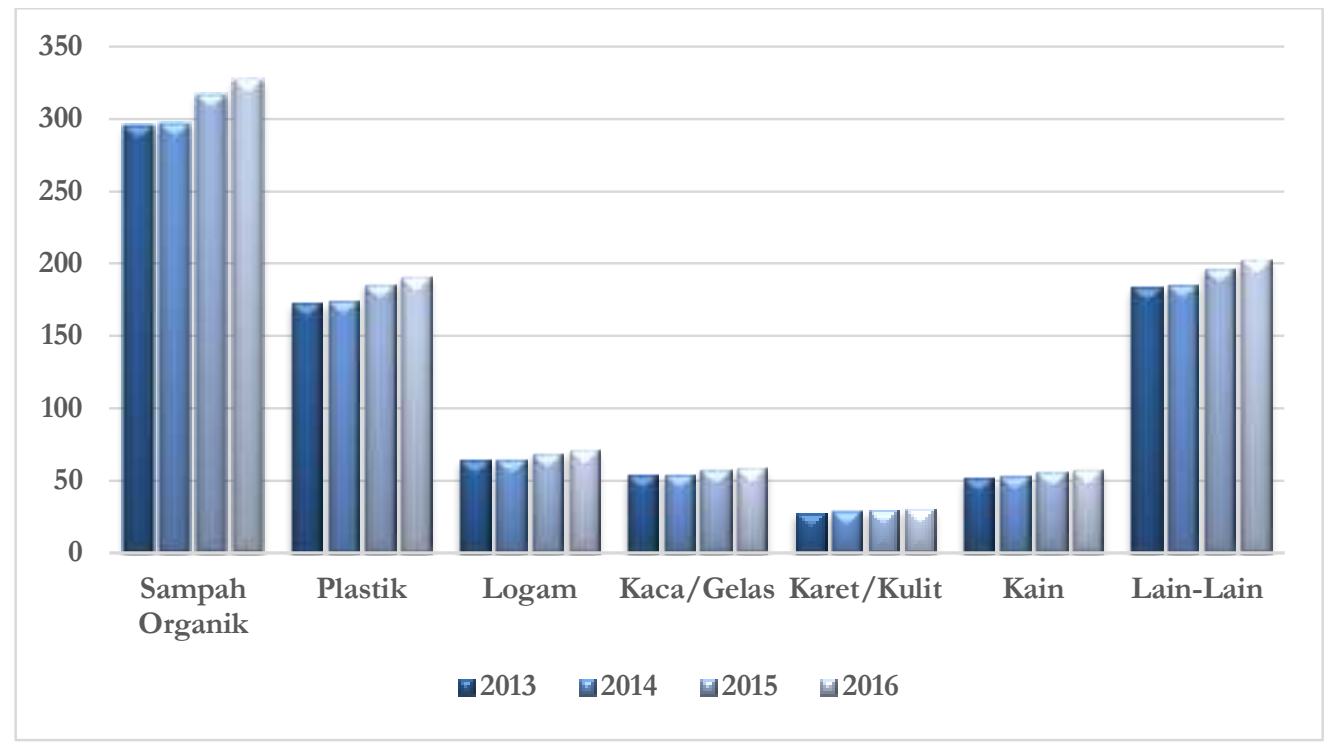

Gambar 1. Volume Sampah Kota Bandung

Sumber : PD. Kebersihan Kota Bandung (2016)

Di sisi lain, sistem penanganan sampah yang saat ini dilakukan dengan metode penumpukan atau penimbunan sampah sudah tidak efektif lagi, mengingat keterbatasan area lahan yang tersedia. Sistem penimbunan sampah dalam jangka panjang akan menyebabkan berbagai macam resiko, salah satu yang terburuk adalah meledaknya senyawa Gas Metana seperti apa yang terjadi di lokasi TPA Leuwigajah pada 25 Februari 2005 silam yang memakan hingga 157 korban jiwa. Tidak hanya itu, kota Bandung juga dihadapkan pada bencana banjir jika musim hujan akibat terjadinya penumpukan sampah di saluran air.

Kota Bandung yang setiap tahun kepadatan penduduknya bertambah, gaya hidup dan kebutuhan yang semakin kompleks, serta kemajuan teknologi, tentunya volume sampah di kota Bandung akan terus meningkat seiring dengan perkembangan kota. Oleh karena itu, perlu adanya penyadaran masyarakat agar lebih perduli terkait masalah sampah. Saat ini Kota Bandung menerapkan gerakan Zero Waste, yaitu gerakan untuk mengurangi dan meminimalisir sampah yang dihasilkan oleh warga. Salah satu prinsipnya adalah 3R (Reduce, Reuse, Recycle). Orientasi konsep Zero Waste meliputi beberapa penanganan, diantaranya 
tersedianya Tempat Pengelolaan Sampah Terpadu (TPST). Saat ini Bandung hanya memiliki 1 lokasi Terpadu yang diresmikan pada tahun 2014 silam. TPS Terpadu menerapkan konsep pengelolaan sampah terpadu yang sejalan dengan prinsip 3R dan konsep Zero Waste yang digalakkan oleh Kota Bandung. Namun dalam menerapkan sistem pengelolaan sampah tersebut, perlu adanya reformasi dan partisipasi dari masyarakat, karena masyarakat merupakan pemeran utama di dalam lingkungannya sendiri. ${ }^{1}$

Keterlibatan masyarakat dalam pengelolaan sampah, merupakan sebuah modal sosial. Modal sosial adalah bagian dari kehidupan sosial berupa jaringan, norma, dan kepercayaan yang mendorong masyarakat untuk bertindak bersama untuk mencapai tujuan-tujuan bersama. Semakin banyak orang dan semakin banyak kesamaan nilai yang dimiliki, maka akan semakin banyak pula modal sosial yang dimiliki. Dengan membangun hubungan dengan sesama dan menjaganya agar terus berlangsung sepanjang waktu, orang mampu bekerja bersama-sama untuk mencapai berbagai hal yang tidak dapat mereka lakukan sendirian. Dengan demikian semakin baik modal sosial yang dimiliki masyarakat, maka semakin efektif dan efisien. Terkait dengan pengelolaan sampah, artikel ini bertujuan untuk mengkaji tentang bagaimana modal sosial masyarakat dalam pengelolaan sampah khususnya di TPS Terpadu.

\section{METODE PENELITIAN}

Metode penelitian yang digunakan adalah kualitatif, dengan tujuan untuk memperoleh data yang mendetail, spesifik dan memperoleh pemahaman kontekstual terkait modal sosial masyarakat dalam pengelolaan sampah. Teknik pengambilan data menggunakan wawancara, observasi, studi literatur dan studi dokumentasi. Informan penelitian adalah petugas TPS Terpadu, aparat pemerintah, tokoh masyarakat dan warga masyarakat. Validasi data dilakukan dengan uji keabsahan dan triangulasi data dengan melakukan perbandingan antara data hasil pengamatan dengan hasil wawancara dan membandingkan apa yang dikatakan orang-orang tentang situasi penelitian dengan apa yang dikatakan sepanjang waktu penelitian.

\section{KERANGKA TEORI/KONSEP}

Pengelolaan sampah merupakan upaya menciptakan keindahan dengan cara mengelola sampah yang dilaksanakan secara harmonis antara rakyat dan pengelola atau pemerintah secara bersama-sama (Neolaka, 2008). Pengelolaan sampah adalah kegiatan yang meliputi

\footnotetext{
1.http:/ /regional.kompas.com/read/2016/10/28/13430151/ikuti.saran.dari.pegiat.asal.inggris.ridwan.kamil.re formasi.pengelolaan.sampah, Harian Kompas edisi Jumat, 28 Oktober 2016).
}

145 | SLSIOGLLBAL : Jurnal Pemikiran dan Penelitian Sasiologi, Vol. I, №. Z, Juni 2017 
pengumpulan, pengangkutan, pemrosesan, pendauran ulang atau pembuangan dari material sampah (Alex, 2012).

Putnam (dalam Field, 2010:51) menyatakan bahwa modal sosial adalah bagian dari kehidupan sosial berupa jaringan, norma, dan kepercayaan yang mendorong partisipan untuk bertindak bersama seacara lebih efektif untuk mencapai tujuan-tujuan bersama. Jaringan sosial memiliki nilai dan kontak sosial yang mempengaruhi produktivitas individu dan kelompok. Hubungan antar individu tumbuh dari jaringan sosial, norma dan kepercayaan. Menurut Damsar dan Indrayani (2009:157), jaringan sosial dalam adalah rangkaian hubungan sosial yang khas diantara sejumlah orang, yang didalamnya terdapat kepercayaan dan kepercayaan tersebut dipertahankan oleh norma yang mengikat kedua belah pihak. Selanjutnya Robert M.Z. Lawang (dalam Damsar dan Indrayani, 2009 : 210) menyatakan bahwa kapital sosial atau modal sosial sebagai semua kekuatan sosial komunitas yang dikonstruksikan oleh individu atau kelompok dengan mengacu pada struktur sosial yang menurut penilaian mereka dapat mencapai tujuan individual atau kelompok secara efektif dan efisien dengan kapital lainnya. Dengan demikian modal sosial merupakan investasi sosial yang meliputi sumber daya sosial seperti jaringan, kepercayaan, nilai dan norma serta kekuatan yang menggerakan struktur hubungan sosial untuk mencapai tujuan individual atau kelompok secara efektif dan efisien dengan kapital lainnya.

\section{PEMBAHASAN}

\section{Pengolahan Sampah Terpadu}

Salah satu upaya pemerintah kota Bandung dalam mewujudkan gerakan Bandung bebas sampah adalah membuat sistem TPS Terpadu. Sistem pengelolaan sampah bertujuan untuk mengurangi residu yang dihasilkan ke TPA. TPS Terpadu menggunakan prinsip pengolahan berbasis 3R (Reduce, Reuse, Recycle) melalui proses pemilahan, pemrosesan dan pemanfaatan sampah yang menghasilkan output barang yang bernilai dan bisa digunakan.

Pengolahan sampah organik TPST Kota Bandung sudah menggunakan biodigester komunal dengan sistem fermentasi bakteri anaerob dengan keluaran olahan berupa pasokan gas dan listrik yang bisa dimanfaatkan. Sampah organik dimanfaatkan menjadi gas bio dengan menggunakan digester untuk memproses sampah organik yang berasal dari rumah dan pasar dengan tujuan untuk mengurangi jumlah sampah yang dibuang ke TPA sekaligus mengkonversikan sampah organik menjadi energi biomethan yang bisa digunakan oleh masyarakat untuk keperluan memasak. Namun, sebelum sampah organik masuk biodigester, 
maka sampah dicacah terlebih dahulu dengan mesin pencacah. Biodigester selain dapat mengurai sampah organik, juga berfungsi mengurai kotoran manusia, yang dapat menghasilkan konversi energi tambahan.

Dalam pemanfaatan sampah dari warga sekitar, TPS Terpadu memberlakukan metode komposting yaitu membuat pupuk kompos dari sampah basah dengan cara penimbunan sampah terpilah yang mudah membusuk. Metode komposting dapat menghasilkan pupuk yang dapat digunakan oleh masyarakat untuk sektor agraris, rumah tangga atau di wilayah pemukiman. Melalui komposting juga diberlakukan sistem urban farming, yaitu sistem penanaman tumbuhan organik di daerah bantaran sungai.

Pada bidang proyek dan bisnis, TPS Terpadu menerapkan program Bank Sampah. TPS Terpadu berupaya untuk meningkatkan pendapatan perusahaan melalui program bank sampah. Selain itu, maksud utama pendirian bank sampah adalah untuk mendukung pelaksanaan prinsip 3R sesuai dengan Peraturan Menteri Lingkungan Hidup Nomor 13 Tahun 2012 tentang Pedoman Pelaksanaan prinsip Reduce, Reuse, Recycle melalui bank sampah. Salah satu kegiatan yang dilakukan di TPS Terpadu dalam mewujudkan Kawasan Bebas Sampah (KBS) adalah program pemilahan sampah. Kegiatan pemilahan sampah merupakan tahap awal dari program Kawasan Bebas Sampah, dimana warga dan kelompok masyarakat merupakan partisipan langsung yang terlibat aktif dalam membantu program tersebut.

\section{Modal Sosial Masyarakat}

\section{Jaringan Sosial}

Jaringan sosial (Damsar dan Indrayani, 2009:157) adalah rangkaian hubungan sosial yang khas diantara sejumlah orang, yang didalamnya terdapat kepercayaan dan kepercayaan tersebut dipertahankan oleh norma yang mengikat kedua belah pihak. Dalam pengelolaan sampah di TPS Terpadu ditemukan adanya hubungan sosial dan relasi sosial yang mengacu pada aspek Bonding, Bridging, dan Linking. Aspek Bonding ditunjukkan oleh adanya kesamaan latar belakang yaitu etnis Sunda dan agama Islam. Hubungan sosial yang terjalin terjadi karena latar belakang yang sama yaitu etnis sunda. Selanjutnya pada kesamaan agama, ikatan sosial terbentuk ketika adanya kegiatan solat berjamaah dan kegiatan pengajian rutin di TPST yang diadakan setiap 1 bulan sekali. Selain itu, kegiatan informal lainnya seperti kegiatan olahraga futsal dan rekreasi bersama juga menghasilkan ikatan sosial yang kuat yang dibentuk melalui interaksi dan komunikasi. Aspek Bridging, yaitu adanya kerjasama antara lembaga TPST dengan kelompok masyarakat seperti Karang Taruna, kelompok komunitas maupun 
kelompok Ibu-ibu PKK. Kerjasama terjalin karena adanya aturan bersama yang harus ditaati, sehingga terjalin komunikasi atau koordinasi diantara kelompok tersebut untuk tercapainya satu tujuan yang diharapkan. Aspek Linking yaitu adanya relasi kerjasama antara TPS Terpadu dengan kelompok masyarakat, organisasi dan perangkat pemerintahan dalam menjalin kesepakatan dan kerjasama. Selain itu TPST juga berkoornasi di dalam menggalakan program Kawasan Bebas Sampah (KBS), agar ke depannya pemilahan sampah dari rumah bisa efektif dijalankan dan efisiensi TPST semakin meningkat, sehingga sistem pengelolaan sampah akan semakin baik ke depannya. Ikatan Sosial yang terbentuk berupa ikatan relasi kerjasama dan gotong-royong yang memperlihatkan aspek modal sosial. Pengelolaan sampah di tingkat masyarakat, dimulai dari tingkat kelurahan dengan membangun relasi hubungan sosial dengan tingkat RW/RT, Karang Taruna dan kelompok PKK. Pada tingkat RW/RT, sistem pengelolaan sampah dilaksanakan diawali dengan kegiatan sosialisasi tentang pengelolaan sampah dan kegiatan Gerakan Pungut Sampah (GPS). Dalam membangun jaringan dengan Karang Taruna, maka Karang Taruna membantu dalam kegiatan sosialisasi dan pengelolaan sampah baik kepada warga maupun ke para pemuda. Selanjutnya dengan kelompok PKK, yaitu melakukan himbauan dalam pengelolaan sampah untuk mengurangi jumlah sampah dengan cara mengumpulkan barang bekas yang dapat dijual untuk kemudian hasilnya dimasukan kedalam kas PKK kelompok.

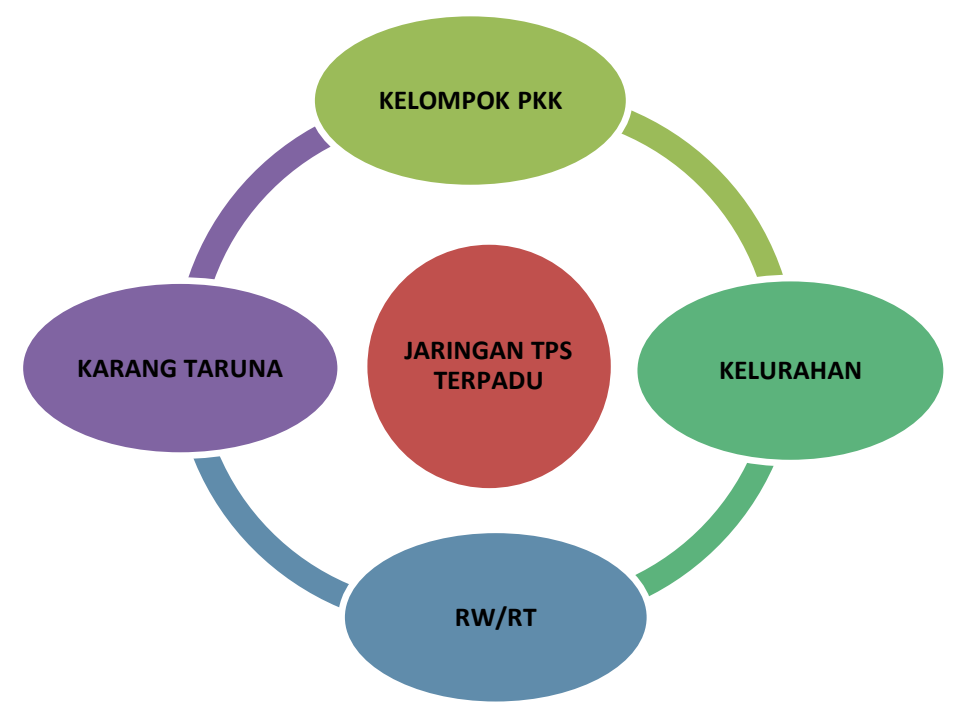

\section{Norma}

Norma sebagai sumber daya sosial merupakan aturan main bersama yang menuntun perilaku seseorang dalam bertindak. Norma memberikan individu suatu cara dimana mereka mengorientasikan diri terhadap orang lain. Norma menuntun kita dalam melakukan definisi 
situasi (Damsar \& Indriyani, 2009 : 216). Norma adalah sekumpulan aturan yang diharapkan dipatuhi dan diikuti oleh anggota masyarakat pada suatu entitas sosial tertentu. Dalam kaitannya dengan modal sosial, norma tidak bisa dilepaskan dengan jaringan, kepercayaan dan nilai. Dengan menggunakan pendekatan pertukaran, manusia adalah makhluk yang rasional, yaitu mempertimbangkan untung dan rugi baik dalam dimensi intrinsik maupun ekstrinsik. Jika suatu pertukaran mendapatkan keuntungan, maka akan muncul pertukaran selanjutnya yang diharapkan mendapatkan keuntungan pula. Resiprositas yang dimiliki norma mengandung hak dan kewajiban bagi pihak yang terlibat dalam pertukaran. Semua pihak harus memiliki tanggung jawab menjaga norma yang terbentuk dalam suatu pertukaran. Jika ada orang yang melanggar norma, maka akan berdampak pada berkurangnya keuntungan para pihak yang terlibat, dan jika hal tersebut dilanggar akan diberlakukan suatu sanksi atau hukuman (Damsar \& Indriyani, 2009:217).

Terdapat norma yang mengatur dalam pengelolaan sampah, baik tertulis maupun tidak tertulis. Norma yang tertulis yaitu berupa standar operasional prosedur pekerjaan, sedangkan norma yang tidak tertulis yaitu berupa pelayanan terhadap masyarakat terkait pengelolaan sampah. Norma tersebut dapat memperkuat aturan dalam mencapai tujuan yang diinginkan oleh bersama agar tetap teratur dan bergerak sesuai dengan fungsinya. Terkait dengan norma yang berlaku di masyarakat dalam pengelolaan sampah, terdapat beberapa sangsi sosial bagi masyarakat diantaranya norma tentang tidak membuang sampah sembarangan, norma dilarang membuang sampah ke bantaran sungai, dan norma untuk menanam pohon di halaman rumah sebagai urban farming. Aspek norma telah memunculkan aturan di masyarakat yang menimbulkan kesadaran dan partisipasi yang harus dimiliki oleh semua warga.

\section{Kepercayaan}

Kepercayaan sebagai unsur dasar di dalam modal sosial. Trust merupakan sikap saling mempercayai di masyarakat dan mereka saling bersatu dengan yang lain dan memberikan kontribusi pada peningkatan modal sosial Fukuyama (1995 : 26). Individu bekerja sama dalam kehidupannya untuk mencapai suatu tujuan yang hendak dicapai. Tidak hanya harus mengenal satu sama lain, tetapi individu perlu saling percaya dan berharap di dalam kerjasama tersebut mereka dapat melakukan sesuatu sesuai dengan apa yang diharapkan oleh pandangan kelompok bersama. Jaringan dengan kepercayaan yang tinggi akan senantiasa berfungsi lebih baik dibandingkan dengan jaringan dengan tingkat kepercayaan yang rendah (Field 2010:103). 
Terkait dengan kepercayaan warga pengelolaan sampah terwujud dari adanya tanggapan positif dari masyarakat dalam pengelolaan sampah. Masyarakat menjadi terpacu di dalam melakukan pengelolaan sampah, karena telah disediakan sarana yang memadai. Selain itu, saat ini masyarakat sudah menjalankan program Kawasan Bebas Sampah (KBS) dengan melakukan kegiatan pemilahan sampah secara bertahap, mulai dari tingkat rumah tangga sampai dengan tingkat kelurahan. Namun demikian, belum semua masyarakat mampu melakukan pemilahan sampah di tingkat rumah tangga.

\section{SIMPULAN}

TPS Terpadu sudah melaksanakan pengelolaan sampah dengan baik melalui modal sosial masyarakat. Hal ini ditunjukkan oleh adanya jaringan, norma dan kepercayaan yang dimiliki oleh masyarakat dalam mencapai tujuan bersama yaitu mewujudkan Kawasan Bebas Sampah (KBS). Pada aspek jaringan, ditemukan adanya hubungan sosial dan relasi sosial yang mengacu pada Bonding, Bridging, dan Linking. Pada aspek norma, pengelolaan sampah berjalan sesuai dengan aturan bersama dan nilai yang berlaku. Pada aspek kepercayaan, adanya respon positif dari masyarakat terhadap pengelolaan sampah khusunya dalam mewujudkan Kawasan Bebas Sampah (KBS).

\section{DAFTAR PUSTAKA}

Alex S. 2012. Sukses Mengolah Sampah Organik Menjadi Pupuk Organik. Yogyakarta: Pustaka Baru Press.

Damsar dan Indrayani. 2009. Pengantar Sosiologi Ekonomi. Jakarta : Kencana.

Ely Chinoy. 1961. "Society, An Introduction to Sociology”. New York: Random House.

Field, John. 2010. Modal Sosial. Bantul : Kreasi Wacana.

Fukuyama, F. 1995. Trust: the social virtues and the creation of prosperity, Hamish Hamilton, London.

Fukuyama, F. 2001. Sosial Capital, Civil Society, and Development. Third Word Quarterly, 22(1):7200.

Hasbullah, J. 2006. Sosial Capital: Menuju Keunggulan Budaya Manusia Indonesia. Jakarta: MRUnited Press.

Irmanputra, Joy. 2013. "Persyaratan Teknis Penyediaan TPS dan TPS-3R dalam rangka Penyelenggaraan". (Executive Director at Indonesian Institute for Infrastructure Studies). Published on Sep 5, 2013. Retrieved December 26, 2016. (https://www.slideshare.net/metrosanita/persyaratan-teknis-tps-dan-tps3r).

Johnson, Doyle P. 1986. Teori Sosiologi Klasik dan Modern. Jilid II.Jakarta: PT.Gramedia.

Lawang, Robert M.Z. 2005. Kapital Sosial dalam Perspektif Sosiologi. FISIP UI PRESS : Universitas Indonesia. 
Levinson. 1964. "Role, Personality and Social Structure". dalam Lewis A. Coser dan Bernard Rosenbery, Sociological Theory, a Book of Readings. New York:The Macmillan Company.

Mead, George H. 1934. "Mind, Self, and Society". Chicago: University of Chicago Press.

Mitchell, J.C. 1969. The Concept and Use of Social Networks, in: J.C. Mitchell

(ed.) Social Network in Union Situation. Manchester: Manchester University Press.

Moleong, Lexy. J. 2007. Metodologi Penelitian Kualitatif. Bandung : Remaja Rosdakarya.

Poloma, Margaret M. 2013. Sosiologi Kontemporer. Jakarta: PT. Raja Grafindo Persada.

Powell, W.W. and L. Smith-Doer. (1994:365). Networks and Economic Life dalam N.J Smelser and R. Swedberg (eds.) The Handbook of Economic Sociology. New York: Princeton University Press.

Putnam, R.D. 1993. Making Democracy Work: civic traditions in modern Italy, Princeton University Press, Princeton

Putnam, R.D. 1995. Turning In, Turning Out: The Strange Disappearance of Social Capital in America. Political Science and Politics.

Putnam, R.D. 1996. Who Killed Civic America?. Prospect ,7,24,66-72.

Ritzer,George. 2012. Dari Sosiologi Klasik Sampai Perkembangan Terakhir Postmodern.Edisi Kedelapan.Yogyakarta:Pustaka Pelajar.

Robert K. Merton. 1949. "Social Theory and Social Structure”. New York: Free Press.

Scheffert, Donna Rae. 2008. Social Capital and Our Community. A Publication of The University of Minnesota Extension Center for Community Vitality.

Soemarwoto, Otto. 1994. Ekologi, Lingkungan Hidup, dan Pembangunan. Jakarta: PT. Penerbit Djambatan.

Znaniecki. "The Social Role and the Social Circle"dalam Sociological, a Book of Readings".

I51 | SGSIOGLOBAL : Jurnal Pemikiran dan Penelitian Sasiologi, Vol. I, №. 2, Juni 2017 